\title{
Sofisticadamente precário: infância e amadorismo contemporâneo
}

\author{
Rodrigo Cascardo ${ }^{1}$
}

\begin{abstract}
Resumo: O presente trabalho dedica-se a refletir acerca do contemporâneo em termo de trânsito, ritmo e proximidade. Acreditamos que o principal traço da contemporaneidade é um amadorismo singular, em nada atrelado aos usuais sentidos pejorativos, propiciado pelo advento de alguns artefatos e artifícios próprios da atualidade. Buscando, ainda, aproximar diferentes contribuições que constituem uma postura crítica em nosso pensamento acerca do contemporâneo, partindo da discussão desencadeada por Giorgio Agamben (2009) investigamos como o forte abalo sofrido no seio da tradição ocidental é favorável ao enfoque que estamos propondo. Por fim, a escolha por nos aproximar, no âmbito das produções discursivas, de certa ideia de infância como estratégia recorrente e de extrema potência, nos fez entrever uma sugestiva contribuição entre arte e ciência entrelaçadas por um entendimento ampliado do brincar, que acena para contornos de nossas futuras ponderações em torno da política e de uma ética na contemporaneidade.
\end{abstract}

Palavras-chave: Contemporâneo. Amador. Infância. Brincar.

\section{Introdução}

São muitos os tipos de relação que podemos estabelecer com o tempo, assim como são, em potencial, diversos os desdobramentos nas formas de se pensá-lo. Podemos dizer que modos diferenciados de experiência do tempo resultam em diferentes formas de ser, estar e se relacionar com o mundo. Naturalmente, estas reverberam na elaboração de formas distintas da leitura de experiências da vida, o que inclui modos diversos de coreografar o corpo-a-corpo com o entorno e o outro, e, consequentemente, diferentes processos de reflexão e produção da expressão humana.

O termo contemporâneo trabalha, obviamente, com um eixo de relações temporais. Corriqueiramente utilizado para articular eventos, fenômenos, acontecimentos e ideias que se relacionam no chamado tempo presente, o contemporâneo fala do atual. Há também outro uso recorrente, e que nos interessa em particular por ilustrar outros entendimentos possíveis, por deflagrar outras chaves de leitura, e, portanto, permitir uma abertura em nossa discussão para uma série de entretempos.

\footnotetext{
${ }^{1}$ Graduado em Psicologia, é Mestre em Letras pela Puc-Rio, onde cursa atualmente o Doutorado, também em Letras. $\mathrm{O}$ artigo apresenta considerações e desdobramentos de sua dissertação Trânsito, ritmo e proximidade: sons do agora, defendida em abril de 2012 e orientada pelo professor Júlio Cesar Valladão Diniz. Compositor, possui também experiência docente e atua nas áreas de Literatura, Cultura, Música Popular e Psicologia. E-mail: rcascardo@gmail.com.
} 
É comum ouvirmos que determinada pessoa foi contemporânea de outra em algum espaço ou atividade em determinada época. Essa relação de proximidade (claramente impressa no prefixo com) ao lembrar um tempo passado nos alerta para o fato de que, mais do que falar de um aqui e um agora, a noção de contemporâneo sugere a ideia de algo que é compartilhado, uma afinidade, um percurso, uma relação. Há uma passagem de MerleauPonty que pode nos acompanhar nessa trajetória: "É preciso que com meu corpo despertem os corpos associados, os 'outros', que não são meus congêneres, como diz a zoologia, mas que me frequentam, que frequento, com os quais frequento um único Ser atual, presente" (MERLEAU-PONTY, 2004, p. 15).

Podemos dizer, junto com o autor, e de acordo com o manejo que propomos, que o contemporâneo trata de uma conexão. Há uma atualidade compartilhada, que não se dá necessariamente no instante do agora, mas no processamento centrífugo de forças que aproximam e produzem um tempo presente entre esses corpos, mantendo-os juntos e em relação.

$\mathrm{Na}$ difícil empreitada de rastrear índices dessa ideia é que Giorgio Agamben busca entrever nas fraturas e cisões dos nossos tempos, limiares de inserção em espaços talvez não frequentados, mas potencialmente presentes. Em torno da reflexão sobre o contemporâneo, o autor traz Nietzsche e Benjamin como pares de importância em seu pensamento para incorporar o debate. É na crítica que ambos os autores formulam ao historicismo que Agamben busca ativar dispositivos que permitam pensar a noção de contemporâneo mais como uma "singular relação com o próprio tempo" (AGAMBEN, 2009, p. 59) do que como a coexistência em uma mesma época.

Partindo de uma síntese cirúrgica de Barthes sobre o tema, Agamben (2009) toma por princípio a ideia de intempestivo - qual trabalhada por Nietzsche em suas considerações para dar um encaminhamento na reflexão que se propõe. O que mais nos interessa na crítica nietzschiana é que, ao questionar a pretensa verdade dos fatos históricos, o autor os apresenta mais como o resultado de um embate de forças, tradições e gerações. Ironizando a pretensa linearidade da concepção histórica (Nietzsche, 2003) nos insinua a possibilidade de entrecruzamentos na relação entre os tempos; uma espécie de ritornello, um eterno retorno que não se trata de uma infinita volta cíclica ao mesmo ponto ou acontecimento, mas uma espiral de repetição em diferença.

O fato de que por tanto tempo tenhamos nomeado nosso tempo e, portanto, refletido sobre nossa existência como sendo um pós é por demais emblemático. Entre esse próximo somos que ainda não veio e aquele esse em que já não estamos, Agamben assinala, quase 
como meta e mote inscritos nas intempestivas considerações nietzschianas, uma exigência de atualidade. Como se essa nova época por vir, que ainda não pudemos nem mesmo nomear com nossa língua, demandasse uma vigília 'antenada', espécie de prontidão presente em torno das formas de lidar com o passado e o tempo em geral. Quando Agamben assinala essa exigência de atualidade, refere-se (com Nietzsche e Benjamin) a assumir uma postura crítica, tomar posição, acertar as contas e redimir os imbróglios pelo embate da afirmação. $\mathrm{O}$ contemporâneo urge no tempo cronológico e o transforma ao pôr em ação "uma relação especial entre os tempos" (AGAMBEN, 2010, p. 28).

Nesse sentido, entrar em relação com determinados instantes do passado consiste em uma prática de contaminação entre forças; a apropriação e o resgate de resíduos como uma ação que busca incorporar elementos de outros tempos sugere a possibilidade de se captar "a configuração em que sua própria época entrou em contato com uma época anterior, perfeitamente determinada" (BENJAMIN, 1994, p. 231). Assumindo que a cultura como um todo está aberta a retornos e ligações aparentemente distantes (porém estreitas, se analisadas a uma distância adequada), podemos dizer que o contemporâneo caminha por um espaço potencialmente paradoxal, equilibrando-se apenas entre a atualização de um "já não" e a sustentação de um "ainda não" (AGAMBEN, 2010, p. 24). É nessa condição paradoxal, acredita Agamben, que para uma pessoa pertencer verdadeiramente ao seu tempo deve cultivar algo de inatual, isto é, estar em certo modo à parte, não coincidindo por inteiro com as pretensões, exigências e modelagens de sua época. Essa espécie de deslocamento no olhar, de sutil desconexão, nos sugere um distanciamento adequado, uma espécie de mobilidade que permita a essa pessoa estar não apenas inserida nos encadeamentos de seu tempo, mas também fora deles, talvez adotando "o costume de ficar sempre meio passo atrás" (BENJAMIN, 2011, p. 126).

Um mundo que se autoproclama pós alguma coisa, é também, de forma complementar, recém-nascido. $\mathrm{O}$ que as distintas perspectivas têm em comum é o estatuto desafiador de um mundo desconhecido. Por representar, em muitos sentidos, uma zona em que o saber construído por nossa tradição é desafiado, não raro, no âmbito das produções realizadas nos campos das artes e das ciências, a infância surge como uma estratégia privilegiada de experiência no mundo, uma nova abordagem de relação pela qual o fenômeno humano tende a buscar "a experiência pessoal renovada" (ANDRADE, 2011, p. 73). É facilmente reconhecível o parentesco entre o fascínio infantil pelos jogos de encaixe e a forma pela qual se dá a mistura de conteúdos pela saturação de ajustes na construção temporal das narrativas contemporâneas. Pôr o tempo em relação talvez seja a brincadeira preferida de nossa época. 
Esse dispositivo (a mistura não sincrônica dos tempos) que não cessa de ser acionado e encenado pode ser identificado nas greves, nas raves, nas curadorias e organizações, na moda e na prática artística, em geral, onde o virtuosismo da técnica passa a ter menor destaque que os códigos de apresentação e circulação do que é produzido. Essa relação com o tempo está presente intensa e extensamente na contemporaneidade, como se todos entendessem (mesmo que automatizados) essa intermediação histórica que os corpos realizam pela "mistura não sincrônica de diferentes tempos" (BHABHA, 2011, p. 132).

O desenho dessa ideia de infância que pretendemos articular sugere uma contribuição entre arte e ciência fundada na inocência da brincadeira e na curiosidade que leva à invenção de si e do mundo, do tempo e dos objetos. É notável (e amplo o inventário) o número de amostras significativas que acenam para a familiaridade do infante para com os elementos do precário e do paradoxo, eixos por excelência do contemporâneo e da vida em geral. É nos trabalhos de Agamben e Winnicott que gostaríamos de nos concentrar para realizar essa exposição. Enquanto Agamben entrevê nessa ideia a possibilidade de um estado anterior à internalização dos protocolos culturais, e, portanto, a potência de "uma aproximação nova à linguagem" (AGAMBEN, 1999, p. 91), a ênfase em Winnicott é a condição relacional de toda criança que permite o desenvolvimento de um espaço intermediário de fenômenos e objetos, esse que é o espaço paradoxal da brincadeira e das experiências culturais. Em outras palavras, é no frescor dessa relação "in-fantil”" (pois não fala), permeada por certa imaturidade e ignorância, para Agamben, e na inocente onipotência lúdica de um espaço entre linguagem e experiência, para Winnicott, que gostaria de sugerir ser a infância em sua trama ágil e cândida aquela que sabe não haver nenhuma "fórmula para a contemporânea expressão do mundo. Ver com os olhos livres" (ANDRADE, 2011, p. 65).

No que se dedica a pensar o brincar e a realidade, tudo em Winnicott (1975) gira em torno do cuidado. Como sabemos, sua teoria funda-se sob a perspectiva do desenvolvimento, partindo da relação mãe-bebê para formular uma instigante construção em torno desse local em que se dão as experiências culturais. É emblemático esse tempero que encaminha Winnicott para o cerne das questões da contemporaneidade. Porque essa forma paradigmática de nossa época se conceber como sistêmica, conexionista, naturalmente engendrada numa complexa teia de emaranhados em rede faz com que, tudo estando tão interligado, o cuidado ganhe um estatuto diferenciado e desdobramentos que se multiplicam.

O chamado espaço potencial, cuja qualidade está atrelada ao contorno, manejo e adaptação ativa do amor zeloso, e por isso não excessivo, é fruto da continuidade com que a criança pode experienciar as sensações de si. Dito isso, esse território intermediário, espaço da 
cultura e da criação lúdica, do gesto espontâneo e da realidade compartilhada, surge da experiência com que o ser humano se defronta na relação entre o que é objetivamente percebido e o que é subjetivamente concebido. É na ampliação que propõe para o entendimento acerca do brincar que Winnicott retoma a criatividade apresentando-a como o eixo da vida saudável. Este não é restrito às crianças ou aos artistas, trata-se de um fenômeno universal. O brincar winnicottiano não vem atrelado ao brinquedo, mas é inseparável da ideia de criatividade de tal forma que a maior preocupação do autor é desenvolver uma metodologia que restitua ou potencialize a capacidade do brincar.

A forma pela qual a contemporaneidade demanda modos de dizer esse frescor, essa novidade, esse novo arranjo para o qual nem mesmo pudemos nomear, nos parece acenar para a intensa reverberação sensível que o campo de considerações em torno da infância aciona em nossa época. Contudo, se há a escolha por essa condição daquele que ainda não fala, ou até qualquer aproximação possível com desdobramentos do campo de enunciados do começar de novo, ela parece repousar numa ética em nada passiva. Naquilo que, junto com Benjamin, na atualidade "rejeitam a imagem do homem tradicional, solene, nobre, adornado com todas as oferendas do passado, para dirigir-se ao contemporâneo nu, deitado como um recém-nascido nas fraldas sujas de nossa época" (BENJAMIN, 2011, p. 116), podemos constatar ser essa pauta produzida por um deslocamento que dribla o que lhe veste de ingenuidade. Nesse ponto, contrapor a ingenuidade à inocência pode ser da maior importância para nos relacionarmos com extensa gama de elementos infantis. A criança como aquela que (pela inocência) consegue alcançar grande complexidade a partir de enunciados simples e gerais, mas desconcertantes. Acreditar na inocência, apostar na força da sutileza, olhar gentil ao outro.

Talvez seja exatamente por isso que a criança seja incomparável no que diz respeito a estar "em condições de poder dar atenção precisamente àquilo que não está escrito, que não está às claras, que não está dito. É por isso que pode ela, também, "nomear as coisas na sua língua" (AGAMBEN, 1999, p. 92). Em Agamben, a infância é acionada como a utopia de uma linguagem da experiência. Movida pela curiosidade, essa criança inventa sua forma de dizer/definir $^{2}$, valorizando os impulsos indutivos, numa atitude de abertura e suspensão em relação aos problemas que coloca. $\mathrm{O}$ amadorismo in-fantil, qual os fragmentos com seus labirínticos ritmos e efeitos em Agamben, processa o artesanato de uma prosa narrativopoética que se assemelha a um compacto-filosófico da ordem de um saber absurdo, a saber,

\footnotetext{
${ }^{2}$ Utilizo aqui em itálico termos sampleados do prefácio escrito por João Barrento para Ideia da prosa, de Agamben, para aproximar os fragmentos escritos pelo filósofo da prática da brincadeira: ambos, sempre tão bons, parecem sempre acabar rápido demais.
} 
feita de modos de não-saber. É o interesse de conhecimento que por si só já contém potencialidades comunicativas; a criança utópica, servindo-se da linguagem como instrumento intuitivo-associativo, não pode deixar de resultar numa epistemologia mais poética que conceptual, fincada na condição de uma antecâmara do conhecimento, espaço que nos remete novamente a Benjamin (especialmente atento à singular escrita/leitura da inocência do mundo infantil) e o que ele chamou por imagens do pensamento.

O extemporâneo para Nietzsche se dá na medida em que para um homem, um povo ou uma cultura é "absolutamente impossível viver, em geral, sem esquecimento", sendo da máxima importância esta faculdade, a do "poder-esquecer" (NIETZSCHE, 2003, p. 15); é exatamente ao poder não saber, ao fazer uma escolha de não dar-se conta, que o intempestivo sugere em sua força plástica pontos de contato com certa zona de não conhecimento. Refletindo sobre o fato de que os "modos que temos de ignorar alguma coisa são tão ou mais importantes talvez do que os modos que temos de a conhecer" (AGAMBEN, 2010, p. 131), Agamben propõe esse espaço que não se trata simplesmente de um não saber, mas sobretudo, da superfície em que devemos saber "mantermo-nos na relação justa com uma ignorância, deixar que um desconhecimento guie e acompanhe os nossos gestos" (AGAMBEN, 2010, p. 132).

Acreditamos que essa condição é fundadora de um registro muito singular de saber, e clivagem valiosa em torno da experiência em nossos tempos, um jeito que virá revelar presença marcante entre os traços da contemporaneidade. Em meio à crescente tensão envolvendo protocolos das indústrias culturais, e à multiplicação das formas de produção, registro e troca de conteúdo, a recorrente aparição da figura do amador em nossos dias parece surgir com uma singularidade intensificada dentro de um amplo arco histórico; não mais atrelado exclusivamente a uma qualidade ou local de fala dentro de um circuito, abre-se na contemporaneidade certa brecha para esse termo ser retomado de forma não apenas pejorativa. Tal fresta que amplia a superfície do amadorismo fazendo dele o principal traço de nossa época surge dos novos usos advindos dos artefatos contemporâneos, bem como de uma mudança na forma pela qual a contemporaneidade estabelece relações com suas culturas.

O amador é um termo que está, claro, extremamente relacionado ao campo do trabalho. Numa linguagem corporativa, trata-se de um funcionário que talvez até seja qualificado para uma função, mas que, dentro de um circuito de técnicas e processos mapeados não é devidamente capacitado. Não lhe coube se apropriar dos recursos e procedimentos, talvez sequer os básicos, não os introjetou, talvez tenha inclusive escolhido não modelar sua prática em torno deles. Inverso e avesso à figura do especialista, o amador não faz da sua produção 
um terreno da perícia; faz o que faz habitando um espaço que não porta o signo do industrial, da repetição serializada - nisso está sem dúvida mais próximo da carpintaria e do artesanato. Não traz a tiracolo uma cartilha ou livro de receitas. Suas repetições se dão sempre contextualizadas, ou seja, em relação e, portanto, em diferença. Ele é um curioso, um interessado.

$\mathrm{O}$ amador de que falamos aqui não é o incompetente e/ou excluído à margem dos roteiros privilegiados de circulação. $\mathrm{O}$ amadorismo é um modo de produção presente em todas as esferas da complexa circuitaria contemporânea, pois desta é o traço mais expressivo. Está intrinsecamente atrelado a uma série de artefatos e inovações da era da informação - as imagens amadoras, por exemplo, perfilam nos grandes veículos pela pauta da interatividade. O que gostaríamos de sugerir é que em meio às novas possibilidades de usos e sociabilidades, a assinatura contemporânea passa por um faça você mesmo, ou até mesmo, um just do it ${ }^{3}$; esse amadorismo não vem acompanhado de um manual de instruções, é simplesmente um tomar posse, é um queimar etapas pela prática, e um forte abalo frente aos dispositivos e agentes da mediação.

A recorrência e adequação desse traço aos nossos tempos não pode ser compreendida de outra forma senão atrelada ao campo de considerações que apresentamos ao sugerir a condição in-fantil da contemporaneidade. Poucas instâncias poderiam ser mais contrárias à noção de especialista do que a criança. Esta e o amador compartilham "a alegria dos que não sabem e descobrem" (ANDRADE, 2011, p. 60). O fato de ambas as figuras construírem seus repertórios de soluções práticas a partir das descobertas de sua curiosidade investigativa nos aproxima da imagem de um menino experimental - para usar expressão de Murilo Mendes que contempla tanto o teor in-fantil do amadorismo que propomos, quanto esse não-saber que faz a criança inventar a descoberta de si mesma. Não há conhecimento a priori, ela experimenta o mundo ao redor pela superfície da inocência: inovando mais a cada dúvida, no que a infância busca traduzir mais o entorno às demandas de seu mundo interno do que adequar-se à realidade externa, gostaria de pensá-la como a fabricação de uma lente autoral, intempestiva, iniciada (pelos modos de ignorar) no olhar sofisticadamente precário (em eterno flerte com o que lhe rodeia) que é próprio do contemporâneo.

A natureza opinativa e dinâmica com que a internet estimula uma pluralidade de trajetos

\footnotetext{
${ }^{3} \mathrm{O}$ uso de um dos mais conhecidos slogans da publicidade se faz para frisar o quanto esse amadorismo não está restrito a um local excluído dos principais circuitos da produção contemporânea. Por esse recorte que propomos, a figura do amador chega a encarnar certa exigência de nossos tempos, tendo sido, enquanto ideia, há muito incorporado pelo mercado. O ritmo acelerado da produção de nossos tempos talvez seja, inclusive, aquilo que demanda e intensifica a importância desse traço amador.
} 
pelo uso das vizinhanças faz com que a figura do amador se adeque naturalmente à rede de relacionamentos contemporâneos. O amador não está circunscrito a um campo disciplinar do saber. Pelo contrário, ele articula um repertório de conhecimento com o qual é capaz de dar continuidade aos questionamentos, encontra modos de dizer que não se concentram num vocabulário técnico-especializado e dirigem-se a perguntas atuais. Se o especialista apresenta uma fala estável em percursos autorizados, a forma como o amador organiza as informações de que dispõe em conhecimento é extremamente pessoal, e o seu repertório é naturalmente formado por essa natureza de trânsito difuso e retalhado do contemporâneo.

É por esse motivo que a produção de conhecimento na contemporaneidade fica ainda mais autoral. A forma pela qual o amador articula um conjunto de informações, dados e fatos em torno de um campo de aproximações íntimas, isto é, próximas, é o que inscreve a adequação do mesmo à conjectura das comunicações contemporâneas. É no conjunto de inovações da atualidade que o amador tanto inventa quanto inventaria uma série de artifícios para sua produção. Tais ferramentas, ao aliar qualidade e praticidade, não raro oferecem em seu suporte a convergência de diferentes utilidades, constituindo-se como um corpo aberto que sugere a criação de usos que se aproximam do artesanato, cujo ofício se faz sem receita.

O amadorismo é, assim, também um mix entre a constatação natural de que não há espaço para uns únicos modos, protocolos ou enunciados, e a urgência com que se deve saber apresentar soluções em curto espaço de tempo, ter a manha do improviso. É por saber o quão frágeis são as pretensas verdades numa era de incertezas, que o amador se torna o personagem por excelência da contemporaneidade, ao encarnar a necessária condição opinativa e acessível do que chamei acima por comunicações contemporâneas. É o amador que consegue fazer o que Gonçalo M. Tavares (2010) se referia ao ressaltar a importância de observar pelo canto do olho como a capacidade de captar o pormenor em sua diferença, pensar ligeiramente, criativamente, estar em condições de rastrear o que está ao lado. No seu contraste à figura do especialista, ao não estar em dia com os protocolos e processos de determinada atividade, ou seja, ao não estar incluído no sistema das práticas organizacionais nascidos no modo da indústria, o amador é aquele que, por não fixar o seu raio de olhar, isto é, por estar aberto ao convite do devaneio ou da deriva, encarna a constatação de ser "por vezes, o olhar distraído (o não obcecado) aquele que capta o mais importante" (TAVARES, 2010, p. 81).

Assim, mantendo-se aquém (e também além como gostaríamos de sugerir) da especialização, o amador encontra um espaço para sua produção estar ao mesmo tempo inserida, mas não sujeita às fórmulas do mercado. Em sua prática não serializada, instável e sem receita, utiliza-se de artifícios e artefatos que o mantém em andamento com o mundo. 
Essa ideia - envolvendo trânsito, ritmo e proximidade - torna-se central não apenas na contemporaneidade, mas para o corpo que viemos rastreando para o contemporâneo nesse breve espaço. Consideramos tais superfícies privilegiadas para buscarmos aproximações sugestivas (nesse terreno de muitas incertezas expressivas) em torno do fenômeno humano nesses tempos de prodigiosas próteses tecnológicas e rearranjo das configurações de mundo. Por fim, pelo âmbito da produção e transmissão de conhecimento, talvez possamos enxergar nesse traço amador a maior inclinação de nossos tempos por buscar realizar produções mais atreladas ao literário do que ao disciplinar.

\section{Conclusão}

O processo de amplo arco histórico pelo qual o amador chega ao centro dos circuitos e sistemas discursivos sincroniza-o com o abalo das separações especializadas de nossa tradição do saber e dos adventos recentes de inovações tecnológicas. Esse amadorismo próprio do contemporâneo já há muito devidamente incorporado pelos mais variados segmentos, é uma zona interessada de confluência de saberes. Um espaço de atrito e fricção que deflagra - e talvez até mesmo provenha dessa constatação - o quão contraditório (ou seja, em nada paradoxal) se torna trabalhar na clausura da especialização e ainda assim buscar fazer da atividade investigativa um instrumento amplo que não apenas contemple várias contribuições na produção de saber, mas também intua encaminhamentos e sugira construções que possam desarticular gargalos na economia dos sistemas de pensamento.

Não são poucos os discursos que apontam a distinção cada vez mais borrada entre a fala do especialista e a especulação do amador como algo nocivo (e perigosamente intensificado pela internet). $\mathrm{O}$ fato de que não raro a figura do amador seja, em seu sentido pejorativo, evocada pelas instâncias e agentes da mediação ${ }^{4}$ nos atenta ainda mais para o fato de que o amadorismo singular da contemporaneidade (apenas falar de suas contribuições com imagens para os telejornais é pouco) provém dessa conjectura ampla e complexa que vem aos poucos sugerindo uma reorientação nos modos de produção - e, portanto, acenando para o início de uma nova configuração nas relações do trabalho e circulação de conteúdo no mundo contemporâneo.

Essa crença no caráter positivo de uma precariedade em prol da expressão de um

\footnotetext{
${ }^{4}$ Logo estes, que supostamente deveriam intensificar a proximidade que a tecnologia da informação nos possibilita, garantir o trânsito e circulação de conteúdos, e também, aos nos facilitar acessos e encaminhamentos, nos permitir gerenciar melhor o ritmo de nossas vidas (de forma que possamos desativar a armadilha que nos engata aceleradamente, e então nos dar o presente de presente).
} 
pessoal é algo com o qual nossa cultura está especialmente familiarizada. É como se nos ligássemos sempre ao saber a partir de uma inteligência prática, sempre inseridos num andamento, apressados em nos precaver dos engessamentos metódicos. O giro rápido da produção contemporânea torna a análise especializada por vezes defasada (e não raro inadequada porque cifrada).

$\mathrm{Na}$ autoria de seu conhecimento, o amador não parte em busca de um inventário cujas amostras apresentem, pelas consonâncias das semelhanças e pelas singulares diferenças, questões a serem enunciadas e formuladas em torno de um recorte. Ele inventa modos de dizer algo sobre aquilo que gostaria de falar sobre, mas ainda não sabe exatamente do que se trata. Trabalha com a famosa "contribuição milionária de todos os erros" (ANDRADE, 2011, p. 61). Aceita e se utiliza dos paradoxos que lhe garantem certa sofisticação precária naturalmente habituado ao andamento com que o fenômeno humano segue criando organizações críticas, mas também organizando criticamente sua criação.

Por fim, ao entediar-se com as especializações, o amadorismo acaba produzindo um campo privilegiado de suportes estratégicos para o seu corpo-a-corpo com as palavras e as coisas, criando dispositivos pelos quais, oral e gestualmente, não apenas busca dizer algo, mas, também, interferir, apreciar e compartilhar.

\section{Referências bibliográficas:}

AGAMBEN, Giorgio. Nudez. Lisboa: Relógio D’Água, 2010.

O que é o contemporâneo? e outros ensaios. Chapecó, SC: Argos, 2009.

. Ideia da prosa. Lisboa: Edições Cotovia, 1999.

ANDRADE, Oswald. A utopia antropofágica. São Paulo: Globo, 2011.

BENJAMIN, Walter. Magia e técnica, arte e política: ensaio sobre literatura e história da cultura. São Paulo: Brasiliense, 2009.

Obras escolhidas: v. II. São Paulo: Brasiliense, 2011.

BHABHA, Homi. O bazar global e o clube dos cavalheiros ingleses: textos seletos de Homi Bhabha. Rio de Janeiro: Rocco, 2011.

MERLEAU-PONTY, Maurice. O olho e o espírito. São Paulo: Cosac Naify, 2004.

NIETZSCHE, Friedrich. Segunda consideração intempestiva: Da utilidade e desvantagem da história para a vida. Rio de Janeiro: Relume Dumará, 2003. 
SANTIAGO, Silviano. Encontros. Rio de Janeiro: Beco do Azougue, 2011.

TAVARES, Gonçalo M. Breves notas sobre a ciência. Florianópolis: Da Casa, 2010.

WINNICOTT, Donald. O brincar e a realidade. Rio de Janeiro: Imago, 1975.

Sophisticatedly precarious: contemporary childhood and amateurism

\begin{abstract}
This article is dedicated to the reflection on the contemporary in terms of transit, rhythm and proximity. We believe that the main feature of the contemporaneity is a singular amateurism definitely not tied to the usual pejorative sense, afforded by the advent of some contemporary artifacts and artifices. In search of different contributions that take a critical position in our thinking, and based mainly on Giorgio Agammben's reflections, and also tuned with our proposals, this reflection has investigated how the strong shock suffered within the Western tradition is favorable to the approach we are proposing. Finally, the choice to approach, within the discursive productions, of a certain idea of childhood as an extremely powerful and recurrent strategy, provides a suggestive glimpse of the contribution of art and science interlaced by an expanded understanding of play that guided our considerations around the politics and ethics in a contemporary setting.
\end{abstract}

Key words: Contemporary. Amateur. Childhood. Play. 